\title{
LXVII. An account of some experiments made in order to determine the velocity with which sound is transmitted in the atmosphere
}

\section{Olinthus Gregory L.L.D.}

To cite this article: Olinthus Gregory L.L.D. (1824) LXVII. An account of some experiments made in order to determine the velocity with which sound is transmitted in the atmosphere, Philosophical Magazine Series 1, 63:314, 401-415, DOI: 10.1080/14786442408644532

To link to this article: http://dx.doi.org/10.1080/14786442408644532

电 Published online: 27 Jul 2009.

Submit your article to this journal $\pi$

Џll Article views: 2

Q View related articles $\sqsubset$ 


\title{
PHILOSOPHICAL MAGAZINE AND JOURNAL.
}

\author{
$30^{\text {th }} J U N E 1824$.
}

LXVII. An Account of some Experiments made in order to determine the Velocity with which Sound is transmitted in the Atmosphere. By Olintuus Gregony, LL.D., Associate Acad. Dijon, Honorary Member of the Literary and Philosophical Society of New York, of the Nere York Historical Society, of the Cambridge Philosophical Society, \&c. Secretary of the Astronomical Society of London and Professor of Mathematics in the Royal Military Academy at Woolwich.*

THE theoretical investigations of different philosophers, in order to ascertain the velocity with which sound is transmitted through the atmosphere, however ingenious and elegant some of them may be, seem to rest too much upon gratuitous assumptions, to allow any cautious inquirer after physical truth to receive them unhesitatingly, except so far as they may be confirmed by accurate experiment. Unfortunately, too, the results of experiment present irregularities both formidable and perplexing; since many of them cannot well be imputed to any want of skill or caution in the conductors of the inquiry.

Feet per Second.

Thus, Mr. Roberts assigns a velocity of . . . 1300

Mr. Boyle . . . . . . . . . . 1200

Mr. Walker and Duhamel . . . . 1338

Mersenne in his treatise De Sonorum Natura,

Causis et Effectibus . . . . . . 1474.

The Florence Academy . • • . . 1148

Cassini de Thury (Mem. Paris. Acad. ann.

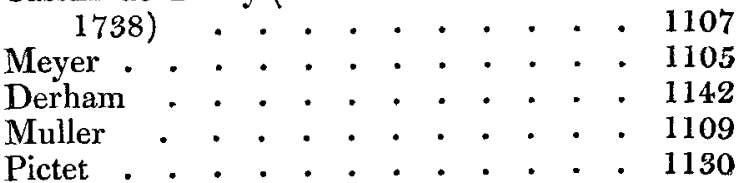

Arago \&c., from experiments in June 1822 ,

give 337.2 metres at the temperature of

$+10^{\circ}$ centigrade... . . $1106.32 \dagger$.

* From the Transactions of the Cambridge Philosophical Society for 1824 .

+ This is the last result of which I had heard previously to the commencerrent of my own experiments.

Vol. 63. No. 314. June 1824.

$3 \mathrm{E}$

The 
The theoretical formula most generally adopted, especially by continental philosophers, is this :

Velocity in horizontal direction $=333 \cdot 4 \cdot 4 \cdot$ met. $\sqrt{1+\cdot 00375 t}$; the metre being $=3.2809$ English feet, and $t$ denoting the indication of the temperature upon the centigrade thermometer.

I am inclined, however, to think that this can only be regarded as an approximative formula; and that we are not yet in a state to receive otherwise than as an approximation any theorem which simply includes the variations of temperature. The air is subject to various classes of changes, indicated by the barometer, thermometer, hygrometer, and anemometer respectively, as well as others probably, for the ascertaining of which we have not yet any appropriate instrument. If we could select these, one by one, ad libitum, and carry experiments first through a moderate range upon the barometric scale, all the other probable elements of modification remaining constant; then, through a sufficiently extensive range upon the thermometric scale, the others remaining invariable, and so on ; the question would soon be set at rest: but this is impossible. It becomes desirable, therefore, to augment the number of recorded facts, as they result from accurate experiments, in order that at some future (and it is hoped no very remote) time a cautions investigator may so select, compare, and classify them, as to deduce a more comprehensive and accurate theorem than is yet known.

With a view to contribute, though in a small degree, to this purpose, I now present an account of a few experiments made by myself in the course of the present year.

My objects were, to ascertain the velocity with which the sound passed over the surface of the earth, over the surface of the water; under different temperatures; in a quiescent state of the atmosphere, and in windy weather; by day and by night; the velocities of direct and reflected sound; and the velocities of sounds of different intensities and produced by different means. As yet the experiments have not been carried to their projected extent; but while I record the results thus far obtained, I lcok forward with hope, that in another year or two I shall be able to complete them satisfactorily.

The instrument with which I measured the intervals of time, was one invented and made by Mr. Hardy, by means of which, with a little previous practice, I could measure an interval accurately to a tenth of a second, and approximatively to a twentieth of a second. The velocity of the wind was ascertained by means of an anemometer; and the barometer and thermometer were of the best construction. 
I employed no hygrometer (much as I wished it); for as yet I am not acquainted with any in whose results $I$ should be inclined to confide. With regard to the distances between the stations at which the sound was emitted and heard, they were in some cases taken from the Ordnance Map of Kent, and verified by new operations; in others they were determined by actual and careful measurement: in others by trigonometrical operations with accurate instruments. The whole were conducted with care; and it would be useless to enter into the detail of them.

Friday, Jan. 3, 1824.-A musquet was fired from the battery near the Royal Artillery Barracks, and the interval of time between the flash and sound was observed at two different distances on the mortar-range, direction nearly north and south.

January 3, half-past 2 P.M., barom. $29 \cdot 7$ inches, Fahr. therm. $45^{\circ}$, rather moist atmosphere, but no rain; very gentle wind blowing in direction nearly perpendicular to that of the range.

Distance from musquet to my station 3600 feet. Six rounds fired: in one the interval of time employed by the sound in passing over the 3600 feet was donbtful: in the other five the intervals were $3^{\prime \prime} \cdot 2.5,3^{\prime \prime} \cdot 3,3^{\prime \prime} \cdot 25,3^{\prime \prime} \cdot 2,3^{\prime \prime} \cdot 26$, the mean of these is $3^{\prime \prime} \cdot 252$.

$$
\frac{3600}{3 \cdot 252}=1107 \text { feet, velocity of sound; therm. } 45^{\circ} \text {. }
$$

Same day, 3 o'clock P.M., barom. 29.64 inches, Fahr. therm. $45^{\circ}$; atmosphere, wind and weather as before.

Distance from musquet to station 3600 feet. Five rounds fired; intervals $3^{\prime \prime} \cdot 2,3^{\prime \prime} \cdot 2,3^{\prime \prime} \cdot 3,3^{\prime \prime} \cdot 3,3^{\prime \prime} \cdot 25$; their mean $3^{\prime \prime} \cdot 25$.

$$
\frac{3600}{3 \cdot 25}=1108 \text { feet, velocity of sound; therm. } 45^{\circ} \text {. }
$$

Same day, half-past 3 P.M., barom. 28.64 inches, Fahr. therm. $45^{\circ}$; atmosphere, wind and weather as before.

Distance from musquet to station 2100 feet. Eight rounds fired. Interval between flash and report in one case doubt. ful: the others were $1^{\prime \prime} \cdot 88,1^{\prime \prime} \cdot 88,1^{\prime \prime} \cdot 9,1^{\prime \prime} \cdot 9,1^{\prime \prime} \cdot 9,1^{\prime \prime} \cdot 9,1^{\prime \prime} \cdot 91$; the mean $1^{\prime \prime} \cdot 896$.

$$
\frac{2100}{1.896}=1108 \text { feet, velocity of sound; therm. } 45^{\circ} \text {. }
$$

Thursday, Jan. 9, three quarters past 7 P.M. dark, but clear, star-light, frosty night. Barom. 29.82 inches, Fahr., therm. $27^{\circ}$. Dry; no wind. Musquets fired from the battery, as before, distance 3600 feet.

Six rounds fired, one doubtful. The other intervals be- 
tween observing the flash and hearing the report, were $3^{\prime \prime} \cdot 25$, $3^{\prime \prime} \cdot 28,3^{\prime \prime} \cdot 3,3^{\prime \prime} \cdot 3,3^{\prime \prime} \cdot 32$; mean $3^{\prime \prime} \cdot 29$.

$$
\frac{3600}{3 \cdot 29}=1094 \cdot 2 \text { feet, velocity of sound; therm. } 27^{\circ} \text {. }
$$

The sound of the same charge, fired from the same musquet, was heard much more intensely on this clear frosty night than in the day-time of January 3 , at the same distance, 3600 feet.

Same day, January 9. Being anxious to extend the experiments to greater distances, I had previously applied to General Ramsey, of the Royal Artillery, the Commandant of the Garrison here, for the use of cannons as well as musquets : these, with his accustomed courtesy and kindness, he immediately ordered to be at my disposal whenever I should need them in the course of my experiments.

On the morning of this day, therefore, I chose a station for the gun on the side of Shooter's Hill, between Severn-Droog Castle and the 8 mile-stone on the Dover road. I selected three other stations from which the gun could be seen with a good Theodolite telescope; one of these was at the entrance of the lane turning from the Dover road to Charlton, between " the Sun in the Sands" and the 7 mile-stone; the second in the Kidbrook Lane which turns off from the Dover road between the 6 mile-stone and " the Sun in the Sands;" and the third on Blackheath, nearly in a continuation of the western wall of Greenwich Park towards the windmills. These three stations are probably 200 feet above the high water-mark in the Thames at Woolwich; and the station at which the gun was placed is still more slevated.

The distances, as accurately measured, were, from the Shooter's Hill station to that in Charlton Lane 6550 feet; from Shooter's Hill to that in Kidbrook Lane 8820 feet; from the Shooter's Hill station to that on Blackheath, 13,440 feet.

The gun employed was a six-pounder, the charge of powder eight ounces. The serjeant-major who remained at the gun was directed to order the men to commence firing at a certain minute by his watch (which was previously made to agree with mine), and then to fire regularly a certain number of rounds at intervals of two minutes: this was the practice throughout the experiments, the gun was always pointed towards me, at a very small elevation, except it be otherwise expressed.

January 9th, noon. Barom. 29.92 inches; Fahr. therm. $33^{\circ}$; weather dry, wind scarcely perceptible, a clear cloudless frosty day. 
Six rounds fired. Interval of passage of sound from Shooter's Hill to Chariton Lane, $5^{\prime \prime} \cdot 9,6^{\prime \prime} \cdot 0,5^{\prime \prime} \cdot 9,6^{\prime \prime} \cdot 0,6^{\prime \prime} \cdot 0$, $6^{\prime \prime} \cdot 0$, their mean $5^{\prime \prime} \cdot 9 \frac{2}{3}$, distance 6550 .

$$
\frac{6550}{59 \frac{2}{3}}=1098 \text { feet, velocity of sound; therm. } 33^{\circ} \text {. }
$$

Same day, January 9, half-past 12, barom. 29.86 inches; Fahr. therm. $33^{\circ}$; weather dry, wind scarcely perceptible. Six rounds fired. Result in reference to one, very doubtful. Intervals of passage of sound from Shooter's Hill to Kidbrook Lane, were $7^{\prime \prime} \cdot 95,8^{\prime \prime} \cdot 0,8^{\prime \prime} \cdot 0,8^{\prime \prime} \cdot 0,8^{\prime \prime} \cdot 05$; their mean 8". Distance 8820 feet.

$$
\frac{8820}{8}=1102 \frac{1}{2} \text { feet, velocity of sound; therm. } 33^{\circ} \text {. }
$$

Same day, January 9, quarter past 1 PM., barom. $29 \cdot 82$ inches; Fahr. therm. $33^{\circ}$; weather dry, wind scarcely perceptible. Five rounds fired ; intervals of the passage of sound between the stations at Shooter's Hill and Blackheath, $12^{\prime \prime} \cdot 2,12^{\prime \prime} \cdot 25,12^{\prime \prime} \cdot 3,12^{\prime \prime} \cdot 24,12^{\prime \prime} \cdot 26$; mean $12^{\prime \prime} \cdot 25$, distance 13440 feet.

$$
\frac{13440}{12 \frac{\mathrm{T}}{4}}=1097 \text { feet, velocity of sound; therm. } 33^{\circ} \text {. }
$$

$\frac{1}{3}\left(1098+1102 \frac{1}{2}+1097\right)=1099 \frac{1}{6}$ feet, mean velocity from the sixteen rounds; therm. $33^{\circ}$.

Monday, February 17, noon. Barom. 29.98 inches; Fahr. therm. $35^{\circ}$. Air humid, but neither rain nor sleet; very genthe wind N.E. by E. Employed bells on the mortar-range on Woolwich Common, lying nearly north and south.

$A$ bell rung at the north station, was heard by a soldier at the south station, who immediately rang another bell, having his arm elevated for the purpose. I stood by the soldier who rang the first bell, and measured the interval of time between the sound of the first bell, and the sound of the second bell when transmitted from the other station.

By several preceding experiments, I estimated the time which elapsed between the moment when the man with the second bell heard the sound from the other, and struck the clapper against his own bell, finding it to be one-fifth of a second; this, therefore, I deducted from the intervals which marked the passage of sound, before I recorded them, as below.

Distance between the two bells 1350 feet; whole distance traversed by the sound 2700 feet. Intervals elapsed (corrected as above) in five experiments; $2^{\prime \prime} \cdot 5,2^{\prime \prime} \cdot 48,2^{\prime \prime} \cdot 44$, $2^{\prime \prime} \cdot 46,2^{\prime \prime} \cdot 42$; mean $2^{\prime *} \cdot 46$.

$$
\frac{2700}{2 \cdot 46}=1098 \text { feet, velocity of sound; therm. } 35^{\circ} \text {. }
$$


Same day, quarter past 12, barom. therm. wind and weather as before.

Distance between the two bells 1650 feet; whole distance 3300 feet. Intervals elapsed in four experiments, $3^{\prime *} \cdot 0,3^{\prime \prime} \cdot 0$, $3^{\prime \prime} \cdot 0,3^{\prime \prime} \cdot 0$.

$$
\frac{3300}{3}=1100 \text { feet, velocity of sound; therm. } 35^{\circ} \text {. }
$$

Same day, half-past 12, barom. therm. wind and weather as before. Distance between the two bells 1800 feet; whole distance 3600 feet. Intervals elapsed in five trials, $3^{\prime \prime} \cdot 25$, $3^{\prime \prime} \cdot 24,3^{\prime \prime} \cdot 26,3^{\prime \prime} \cdot 25,3^{\prime \prime} \cdot 25$; mean $3^{\prime} \cdot 25$.

$$
\frac{3600}{3 \cdot 25}=1108 \text { feet, velocity of sound; therm. } 35^{\circ} \text {. }
$$

$\frac{1}{3}(1098+1100+1108)=1102$ feet, mean velocity from this day's experiments; therm. $35^{\circ}$.

Friday, May 23. This morning there was a tolerably brisk wind blowing from the S.W. by W. nearly in the direction of my Charlton and Kidbrook stations from Shooter's Hill. Of this I gladly availed myself, as the morning was in other respects favourable, in order to ascertain what would be the effect of such a wind upon the velocity. Cloudy, air humid, but no rain.

I measured the velocity of the wind frequently with an anemometer, and found it vary between 22 and 26 feet, the mean 24. feet.

The gun a six-pounder, charge $8 \mathrm{oz}$. of powder. $11 \mathrm{~A}$.M. gun at Shooter's Hill, sound heard at Charlton Lane, distance 6550 feet. Barom. 29.66 inches. Fahr. therm. 58 ${ }^{\circ}$, air humid. Six rounds fired; the intervals were $6^{\prime \prime} \cdot 1,6^{\prime \prime} \cdot 05,6^{\prime \prime} \cdot 0$, $6^{\prime \prime} \cdot 05,6^{\prime \prime} \cdot 0,6^{\prime \prime} \cdot 04$; their mean $6^{\prime \prime} 037$.

$\frac{6550}{6 \cdot 037}=1085$ feet, velocity of sound, when opposed by the wind.

Same day, quarter past 1 P.M., barom. 29.67 inches, Fahr. therm. $60^{\circ}$; air drier. Gun at Charlton Lane. Sound heard at Shooter's Hill. Distance 6550 feet. Five rounds fired: the intervals were, $5^{\prime \prime} \cdot 65$ doubtful, $5^{\prime \prime} \cdot 8,5^{\prime \prime} \cdot 78,5^{\prime \prime} \cdot 76$, $5^{\prime \prime} \cdot 78$, omitting the first, the mean interval of the other four is $5^{\prime \prime} \cdot 78$.

$\frac{6550}{5 \cdot 78}=1133 \frac{1}{2}$ feet, velocity of sound, when aided by the wind.

$\frac{1}{2}\left(1085+1133 \frac{1}{2}\right)=1109 \frac{1}{4}$ feet inferred velocity of sound independently of the wind; therm. $59^{\circ}$.

And $\frac{1}{2}\left(1133 \frac{1}{2}-1085\right)=24 \frac{1}{4}$ inferred velocity of the wind 
at the times of the experiment, supposing it to be nearly the same at both times. This agrees quite as nearly as could be expected with the mean velocity of the wind determined by the anemometer.

Same day, May 23, half-past 11 A.M., barom. $29 \cdot 67$ inches: Fahr. therm. $58^{\circ}$ : air humid; wind as before.

Before the gun was removed from Shooter's Hill, six rounds more were fired. The intervals in which the sound reached Kidbrook Lane, were $8^{\prime \prime} \cdot 1,8^{\prime \prime} \cdot 125,8^{\prime \prime} \cdot 13,8^{\prime \prime} \cdot 15,8^{\prime \prime} \cdot 1$, and one very doubtful. The mean of these is $8^{\prime \prime} \cdot 121$. Distance 8820 feet.

$$
\frac{8820}{8 \cdot 121}=1086 \text { feet, velocity of sound, opposed by the wind. }
$$

Here the sound was but just audible, the wind diminishing its intensity exceedingly.

Same day, therefore, the gun was removed to Kidbrook Lane, while I went back to Shooter's Hill.

Half-past 12, barom. 29.67 inches; Fahr. therm. $60^{\circ}$; air drier; wind as before. Six rounds were fired. The intervals between the flash and the report were $7^{\prime \prime} \cdot 8,7^{\prime \prime} \cdot 7,7^{\prime \prime} \cdot 8$, $7^{\prime \prime} \cdot 78,7^{\prime \prime} \cdot 78$, and one very doubtful; mean $7^{\prime \prime} \cdot 77$.

$$
\frac{8820}{7 \cdot 77}=1136 \text { feet, velocity of sound, when aided by the wind. }
$$

$\frac{1}{2}(1086+1136)=1113$ feet, inferred velocity of the sound independent of the wind; therm. $59^{\circ}$. $\frac{1}{2}(1136-1086)=25$ feet inferred velocity of the wind, nearly as before.

The same day, May 23, in the afternoon, the wind subsided, so as not to exceed 6 or 8 feet per second, while the temperature of the air remained nearly the same. I anxiously availed myself of this opportunity to ascertain the velocity of the sound, when scarcely affected by the wind. Mortars and howitzers were firing from the battery, the former at an angle of $45^{\circ}$, the latter at low angles for Ricochet practice. At $3 \frac{1}{2}$ P.M. when the barom. was at 29.68 inches, Fahr. therm. at $60^{\circ}$, the sun shining, I took a station 3100 feet from the battery, and in a direction nearly perpendicular to that of the wind, then gently blowing. I observed the intervals between the flash and the report, for six rounds, of which the first three were with howitzers, the next three with mortars; these were successively $2^{\prime \prime} \cdot 77,2^{\prime \prime} \cdot 76,2^{\prime \prime} \cdot 79,2^{\prime \prime} \cdot 79,2^{\prime \prime} \cdot 8,2^{\prime \prime} \cdot 8$; their mean $2^{\prime \prime} \cdot 786$.

$$
\frac{3100}{2 \cdot 786}=1112 \text { feet, velocity of sound; therm. } 60^{\circ} \text {. }
$$

In these latter experiments the sound was very distinct and sharp : 
sharp: the result, though drawn from a short distance, serves to confirm the preceding results on the same day.

Thursday, August 7. On this day, which was cloudy, but with intervals of sunshine, I employed the same six-pounder as before, sometimes with charges of 8 ounces of powder, at others, when the distance required it, with 12 ounces. The wind was quite brisk, varying in velocity from 30 to 35 feet, as determined by an anemometer.

At eleven o'clock A.M., barom. $29 \cdot 80$ inches; Fahr. therm. $66^{\circ}$; air dry, cloudy, but sun shining; wind nearly opposing the motion of the sound, and having a velocity of 30 feet. Six rounds were fired from Shooter's Hill. The intervals occupied in the passage of sound from thence to Kidbrook Lane, distance 8820 feet, were $8^{\prime \prime} \cdot 1,8^{\prime \prime} \cdot 15,8^{\prime \prime} \cdot 16,8^{\prime \prime} \cdot 13,8^{\prime \prime} \cdot 13,8^{\prime \prime} \cdot 12$; their mean, $8^{\prime \prime} \cdot 13$.

$$
\frac{8820}{8 \cdot 13}=1085 \text { feet, velocity of sound, when opposed by the }
$$
wind.

Same day, August 7, quarter past 1 P.M., barom. therm. wind and weather as before.

The gun being placed in Kidbrook Lane, I went to the station on Shooter's Hill. Six rounds were fired, and the intervals occupied in the transmission of the sound were $7^{\prime \prime} \cdot 7$, $7^{\prime \prime} \cdot 75,7^{\prime \prime} \cdot 68,7^{\prime \prime} \cdot 67,7^{\prime \prime} \cdot 72,7^{\prime \prime} \cdot 68$; their mean $7^{\prime \prime} \cdot 7$.

$$
\frac{8820}{7 \cdot 7}=1145 \frac{1}{2} \text { feet, velocity of sound, when aided by a wind }
$$
of about the same velocity as the former.

$\frac{1}{2}\left(1085+1145 \frac{I}{2}\right)=1115 \frac{1}{4}$ feet, velocity of sound; therm. $66^{\circ}$,

$\frac{1}{4}\left(1145 \frac{1}{2}-1085\right)=30 \frac{1}{4}$ feet, velocity of the wind.

Same day, August 7 , half-past 11 A.M., barom. 29.80 inches; Fahr. therm. $64^{\circ}$, the wind blowing in the same direction as before, with (an estimated) velocity of 30 feet; air dry, cloudy, no sun. The same six-pounder gun was fired from the Shooter's Hill station with a charge of 12 ounces of powder, and I took a station on Blackheath 20 feet further than on January 9 , its distance being 13,460 feet from the gun.

Six rounds were fired; one of the intervals was very doubtful ; the others were $12^{\prime \prime \cdot} \cdot 4,12^{\prime \prime} \cdot 38,12^{\prime \prime} \cdot 42,12^{\prime \prime} \cdot 38,12^{\prime \prime} \cdot 4,12^{\prime \prime} \cdot 4$; their mean $12^{\prime \prime} \cdot 396$.

$$
\frac{13460}{12 \cdot 396}=1085 \cdot 8 \text { feet, velocity of sound when opposed by the }
$$
wind.

Being fearful of bringing the gun to Blackheath, in the vicinity 
cinity of so many carriages as were incessantly passing, I could not here avail myself of the benefit of comparing the above intervals with those in which the direction of the transmission should be reversed. I venture, therefore, to add the velocity of the wind to that of the sound, as obtained by the experiment, and thus obtain $1085 \cdot 8+30=1116$ feet nearly, for the velocity of sound, the therm. standing at $64^{\circ}$.

Monday, August 18. On this day, the same six-pounder gun was placed upon the wharf by the side of the Thames in the Royal Arsenal, and I took a station at the opposite extremity of the Gallion's Reach, not far from the mouth of Barking Creek; the distance from the gun was 9874 feet, the time of high water there, on that day, was about 11 o'clock A.M.

At half past 11 A.M., barom. $29{ }^{\circ} 84$ inches; therm. $66^{\circ}$; air dry, sky rather cloudy: very gentle wind nearly perpendicular to the line of transmission of the sound. Six rounds were fired with the muzzle of the gun towards me: the intervals were $8^{\prime \prime} \cdot 8,8^{\prime \prime} \cdot 84,8^{\prime \prime} \cdot 86,8^{\prime \prime} \cdot 86,8^{\prime \prime} \cdot 83,8 " \cdot 85$; their mean $8 " .84$.

At three quarters past 11 A.M., barom. \&c. as before; six more rounds were fired, the gun muzzle being directed from us (up the river) in a horizontal angle of about 140 degrees: the intervals were $8^{\prime \prime} \cdot 86,8^{\prime \prime} \cdot 84,8^{\prime \prime} \cdot 82,8^{\prime \prime} \cdot 82,8^{\prime \prime} \cdot 85,8^{\prime \prime} \cdot 86$; their mean $8^{\prime \prime} \cdot 841$.

$\frac{9874}{8.84}=1117$ feet, velocity of sound; therm. $66^{\circ}$, over a surface of water.

Although there was no perceptible difference in the mean intervals occupied by the transmission of sound, in the two different directions of the gun, yet there was a considerable modification of the intensity; the sound being much weaker when the gun muzzle was directed westerly, up the river, than when it was pointed down Gallion's Reach, towards the place where I stood. In the former case, too, besides the first report, which was marked and distinct, though comparatively feeble, there was a series of audible re-percussions, at intervals of about a tenth of a second, and gradually dying away: these, I conjecture, were reflected sounds from the faces of storehouses and other buildings standing on or near the side of the river at Woolwich.

Same day, August 18, one o'clock P.M., barom. 29:82 inches, Fahr. therm. $66^{\circ}$; fair, but cloudy; scarcely any wind: I took a station on the Essex bank of the Thames perpendicularly opposite the large storehouse on Roff's Wharf at Woolwich, in order to ascertain the interval occupied by both Vol. 63. No. 314. June 1824. 
the direct and the reflected transmission of the sound from a musquet fired by my side, and returned in an echo from the front of the said storehouse. 'The distance from my station to the front of the storehouse, determined carefully by a trigonometrical operation, was 1523 feet.

Of eight rounds fired from the musquet, I failed twice in the appreciation of the interval between the sound and the returning echo, from a very wrong estimate of its probable duration; and that from an erroneous impression as to the time observed by Dr. Derham in a similar experiment*. Of the remaining six rounds, the musquet pointed across the river, the intervals were $2^{\prime \prime} \cdot 7,2^{\prime \prime} \cdot 75,2^{\prime \prime} \cdot 74,2^{\prime \prime} \cdot 72,2^{\prime \prime} \cdot 75,22^{\prime \prime} \cdot 74$; their mean $2^{\prime \prime} \cdot 73$.

Next, three rounds were fired, the musquet being pointed directly from the river; the intervals were $2^{\prime \prime} \cdot 7,2^{\prime \prime} \cdot 73,2^{\prime \prime} \cdot 76$; mean as before.

Lastly, four rounds were fired along the bank, at an elevation of about $45^{\circ}$; the intervals were $2^{\prime \prime \cdot} \cdot 75,2^{\prime \prime} \cdot 7,2^{\prime \prime} \cdot 73,2^{\prime \prime} \cdot 74$; mean as before.

Distance occupied by the direct and the reflected sounds 3046 feet.

$\frac{3046}{273}=1116$ feet velocity of sound across a surface of water, half direct, half reflected; therm. $66^{\circ}$.

The near agreement of this with the former result on the same day, serves to confirm the opinion that direct and reflected sounds move with the same velocity.

Thursday, August 21, three o'clock P.M., barom. 29.86 inches, Fahr. therm. $64^{\circ}$; clear sunshine; wind scarcely perceptible, westerly.

Mortars were firing from the battery, and I took a station 3900 feet south of it. I observed the intervals between the flash and the report in six successive rounds: they were $3^{\prime \prime} \cdot 5$, $3 \prime \cdot 5,3^{\prime \prime} \cdot 48,3^{\prime \prime} \cdot 52,3^{\prime \prime} \cdot 5,3^{\prime \prime} \cdot 5$, respectively; the mean being $3 " \cdot 5$.

$$
\frac{3900}{3.5}=\frac{7800}{7}=1114 \frac{2}{7} \text { feet, velocity of sound, therm. } 64^{\circ} \text {. }
$$

These are all the experiments in reference to the velocity

* He made it 3 seconds, by means of a half-second pendulum. My erroneous recollection of his experiment led me to anticipate an interval of between 4 and 5 seconds. I could not account for the supposed discrepance until after my return home, when, on examining Derham's paper, and computing the real breadth of the river from my trigonometrical operation, I found the correspondence of the two experiments to be quite as great as could be expected, considering the different natures of the chronometers employed, and the varying breadth of the river. 
of sound, as transmitted through the atmosphere, which I have yet been able to make. Their chief results may be brought into one view as below.

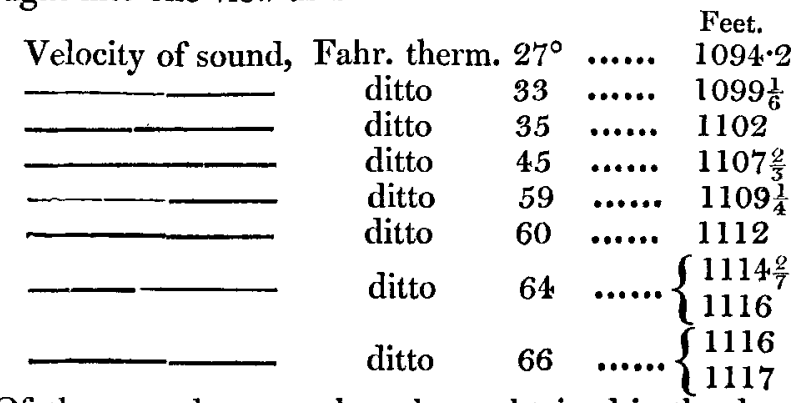

Of these results, some have been obtained in the day-time, others in the night; some when the sound has been transmitted over the surface of the earth, others when it has been transmitted over the surface of water; some are the result of direct sound, others of both direct and reflected sound; some from the report of cannons, others of musquets, others from the sound of bells.

Were these the only experiments on the subject that had ever been made, I should not regard them sufficiently extensive to justify me in deducing from them even an approximative rule. But as they have been made with great care, I may at least venture to present a rule, which, while it includes with only slight discrepancies all the preceding results, is simple enough to be easily recollected by practical men; and may, perhaps, be employed in our own climate. It is this :

At the temperature of freezing $33^{\circ}$, the velocity of sound is 1100 feet per second.

$\left.\begin{array}{l}\text { For lower temperatures deduct } \\ \text { For higher temperatures add }\end{array}\right\}$ half a foot.

$\left.\begin{array}{c}\text { From the } 1100 \\ \text { to the } 1100\end{array}\right\}$ for every degree of difference from $33^{\circ}$ on Fahr. therm.; the result will show the velocity of sound, very nearly, at all such temperatures.

Thus, at the temperature of $50^{\circ}$, the velocity of sound is, $1100 \times \frac{1}{2}(50-33)=1108 \frac{1}{2}$ feet.

At temperature $60^{\circ}$, it is $1100+\frac{1}{2}(60-33)=1113 \frac{1}{2}$ feet; agreeing with the experimental result quite within the limits of a practical rule.

The theorem 333.4. met. $\sqrt{1+00375 t}$, before cited, gives nearly 1094 feet for the velocity at the freezing point; and 1114 feet for the temperature $10^{\circ}$ centigrade, or $50^{\circ}$ Fahrenheit: thus occasioning a greater augmentation to the velocity 3 F 2 
in the higher temperatures, than my experiments seem to indicate.

The above practical rule, so far as it may be entitled to confidence, may be useful, 1 st, to the military man in determining the distance of an enemy's camp, of a fortress, a battery, \&c.; 2d, to the sailor, in determining the distance of another ship, \&c.; $3 \mathrm{~d}$, to the land-surveyor in ascertaining the length of base lines, \&c. in conducting the survey of a lordship or county; 4 th, to the philosophic observer, in appreciating the distances of thunder-clouds during a storm. Yet in either of these applications the rule must be regarded as approximative only; because few practical men can be expected to possess a time-measurer for less intervals than tenths of seconds (if, indeed, so small) : and an error of a tenth of a second, will occasion a mistake of from 37 to 40 yards in the estimate of the distance. Beyond this, however, the error need scarcely ever extend; because a mean of 5 or 6 careful experiments will usually give the interval to a degree of correctness far within the limits just specified. Indeed, an error of from 30 to 40 yards in a distance of three or four miles, will, on most occasions, where such approximative estimates are required, be of but small consequence. When the distance exceeds four miles, this method of approximating to it can only be employed under favourable circumstances of a very quiescent atmosphere, \&c.: on which account, I felt scarcely any desire to extend my own experiments to stations more remote from each other, than those which I selected on Shooter's Hill and Blackheath.

Combining the results of experiments here recorded with those which have been formerly deduced by Derham and others, we may, I think, conclude unhesitatingly:

1st, That sound moves uniformly; at least, in a horizontal direction, or one that does not deviate greatly from horizontality.

$2 \mathrm{~d}$, That the difference in intensity of a sound makes no appreciable difference in its velocity*.

3d, Nor, consequently, does a difference in the instrument from which the sound is emitted.

4th, That wind greatly affects sound in point of intensity; and that it affects it, also, in point of velocity.

5 th, That when the direction of the wind concurs with that of the sound, the sum of their separate velocities gives the $a p$ parent velocity of sound; when the direction of the wind op-

* The consecution of the notes in a tune, notwithstanding the difference in their intensity, being uninterrupted when heard at a distance, furnishes an elegant and dccisive confirmation of this proposition. 
poses that of the sound, the difference of the separate velocities must be taken.

6th, That in the case of echoes, the velocity of the reflected sound, is the same as that of the direct sound.

$7 \mathrm{th}$, That, therefore, distances may frequently be measured by means of echoes.

8th, That an augmentation of temperature occasions an augmentation of the velocity of sound; and vice versü.-(See Newton, Principia, lib. 2. prop. 50. Parkinson's Mechanics, vol. ii. p. 148.)

The inquiries with regard to the transmission of sound in the atmosphere*, which, notwithstanding the curious investigations of Newton, Laplace, Poisson, and others, require the further aid of experiment for satisfactory determination, are, I think, the following; viz.

1st, Whether hygrometric changes in the atmosphere have much or little influence on the velocity of sound?

$2 \mathrm{~d}$, Whether barometric changes in the atmosphere have much or little influence?

3d, Whether, as Muschenbroek conjectured, sound have not different degrees of velocity, at the same temperature, in different regions of the earth? And whether high barometric pressures would not be found (even independently of temperature) to produce greater velocities?

4 th, Whether, therefore, sound would not pass more slowly between the summits of two mountains, than between their bases?

5th, Whether sound, independently of the changes in the nir's elasticity, move quicker or slower near the earth's surface, than at some distance from it?-(See Savart's interesting papers on the communication of sonorous vibration.)

6th, Whether sound would not employ a longer interval in passing over a given space, as a mile, vertically uproards, than in a horizontal direction? and, if so, would the formula which should express the relation of the intervals include more than thermometric and barometric coefficients?

7 th, Whether or not, the principle of the parallelogram of forces may be employed in estimating the effect of wind upon sound, when their respective velocities do not aid, or oppose each other in the same line, or nearly so?

8th, Whether those eudiometric qualities, generally (whether hitherto detected or not) which affect the elasticity of the air,

* I say nothing in this paper of the transmission of sound through the gases, along metallic conductors, \&c. These furnish a most interesting department of separate inquiry. 
will not proportionally affect the velocity of sound? and if so, how are the modifications to be appreciated?

To the experimental solution of some of these inquiries I hope to devote myself at no very remote period: but others of them, it is evident can only be satisfactorily answered, if ever, by means of a cautious classification of skilful experiments made by various philosophers in different parts of the globe.

Royal Military Academy, Woolwich, Ouinthus Gregory. Oct. 25, 1823.

P.S. Since the above paper was drawn up, a friend has favoured me with the perusal of Mr. Goldingham's account of his experiments in reference to the velocity of sound, made at Madras. From this very interesting dissertation I shall venture to transcribe the following table of the mean motion of sound for each month of the year at Madras.

\begin{tabular}{|c|c|c|c|c|}
\hline \multirow{2}{*}{ Month. } & \multicolumn{3}{|c|}{ Mean height of } & \multirow{2}{*}{$\begin{array}{l}\text { Velocity } \\
\text { in a } \\
\text { Second. }\end{array}$} \\
\hline & Barometer. & Thermometer. & Hygrometer. & \\
\hline January ... & $\begin{array}{l}\text { Inches. } \\
30 \cdot 124\end{array}$ & $\begin{array}{l}\text { Degrees. } \\
79^{\circ} 05\end{array}$ & $\begin{array}{l}\text { Dry. } \\
6.2\end{array}$ & $\begin{array}{l}\text { Feet. } \\
1101\end{array}$ \\
\hline February & $30 \cdot 126$ & $78 \cdot 84$ & $14 \cdot 70$ & 1117 \\
\hline March & 30.072 & $82 \cdot 30$ & 1522 & 1134 \\
\hline April...... & $30 \cdot 031$ & $85 \cdot 79$ & $17 \cdot 23$ & 1145 \\
\hline May .. & $29 \cdot 892$ & $88 \cdot 11$ & $19 \cdot 92$ & 1151 \\
\hline June ... & $29 \cdot 907$ & $87 \cdot 10$ & $24 \cdot 77$ & 1157 \\
\hline July ... & $29 \cdot 914$ & $86 \cdot 65$ & $27 \cdot 85$ & 1164 \\
\hline August ... & $29 \cdot 931$ & $85 \cdot 02$ & $21 \cdot 54$ & 1163 \\
\hline September & $29 \cdot 963$ & $84 \cdot 49$ & $18 \cdot 97$ & 1152 \\
\hline October... & $30 \cdot 058$ & $84 \cdot 93$ & $18 \cdot 23$ & 1128 \\
\hline November & $30 \cdot 125$ & $81 \cdot 35$ & $8 \cdot 18$ & 1101 \\
\hline December & $30 \cdot 087$ & $79 \cdot 37$ & $1 \cdot 43$ & 1099 \\
\hline
\end{tabular}

These results serve, as far as they go, to confirm the suspicions which I have long entertained, that the velocity of sound is somewhat different in different climates; and that hygrometric changes have more influence than has usually been imputed to them by theorists. The velocity varies from 1099 to 1164 feet, while the barometric range does not exceed a quarter of an inch, and the thermometer varies only from about $78^{\circ}$ to $88^{\circ}$. But the indications of hygrometric change are considerable, passing from $1^{\circ}$ to nearly 28 degrees. Un- 
fortmately, however, we are not able to make such satisfactory deductions from these curious experiments as they might have furnished, had $\mathrm{Mr}$. Goldingham described the construction of his hygrometer, and the fixed points, or the extent of its scale.

Royal Military Academy, Nov. 8, 1823.

LXVIII. On the New Method of Gauging proposed by Dr. Young. By Mr. W. Wistman.

To the Editors of the Philosophical Magazine and Journal.

Gentlemen,

IN the Journal of Science, No. 32, there appears a Report, I made to the Honourable Commissioners of the Customs by Dr. Young, respecting improvements in Gauging. The matter being thus made public, I shall now take the liberty, through your permission, to offer a few observations on the occasion.

The advantages which Dr. Young states, in the Report just mentioned, would be derived from the adoption of his invention, are, the shortening the operation of casting the full content,-abolishing the practice of making a discretionary allowance in the length of each cask supposed adequate to reduce such cask to the middle frustum of a spheroid, - and at the same time attaining at least an equal degree of accuracy with the old method.

The detailed operation of casting the content; at present in use, is this :- The beginning of the first line is set to the head diameter on the second line; the number on the third line, standing against the bung diameter on the second line, is noted; against this number on the first line is found the mean diameter on the second line. Next, the end of the slide is set to the length on the fourth line; and against the mean diameter on the fifth line is found the full content on the fourth line.

The operation which Dr. Young proposes to substitute for the above, and for the method of allowances, is this:-The head and bung diameters on the first and second lines are brought together, and against the length on the third line is the full content on the fourth line.

The formula upon which this operation depends, is a most scientific and ingenious invention; and were it possible to invent a rule which would always give the content, at a single setting of the slide, sufficiently near the truth in all the varie- 